\title{
Experimental Researches on Long-Term Strength of Granite Gneiss
}

\author{
Lin Liu ${ }^{1,2}$ and Weiya $\mathrm{Xu}^{1,2}$ \\ ${ }^{1}$ Key Laboratory of Ministry of Education for Geomechanics and Embankment Engineering, Hohai University, Nanjing 210098, China \\ ${ }^{2}$ Research Institute of Geotechnical Engineering, Hohai University, Nanjing 210098, China
}

Correspondence should be addressed to Lin Liu; linliunj@hotmail.com

Received 9 June 2015; Accepted 6 September 2015

Academic Editor: Fernando Lusquiños

Copyright (C) 2015 L. Liu and W. Xu. This is an open access article distributed under the Creative Commons Attribution License, which permits unrestricted use, distribution, and reproduction in any medium, provided the original work is properly cited.

It is important to confirm the long-term strength of rock materials for the purpose of evaluating the long-term stability of rock engineering. In this study, a series of triaxial creep tests were conducted on granite gneiss under different pore pressures. Based on the test data, we proposed two new quantitative methods, tangent method and intersection method, to confirm the long-term strength of rock. Meanwhile, the isochronous stress-strain curve method was adopted to make sure of the accuracy and operability of the two new methods. It is concluded that the new methods are suitable for the study of the long-term strength of rock. The effect of pore pressure on the long-term strength of rock in triaxial creep tests is also discussed.

\section{Introduction}

Long-term strength is a key and typical mechanical parameter in rock creep behavior. The creep mechanical behavior of rock is very important to evaluate the stability and safety of rock engineering, such as high slope rock engineering, underground cavern rock engineering, dam base rock engineering, and underground oil storage project [1-5]. Meanwhile, the understanding of long-term strength is of great importance for further development of knowledge in the field of rock mechanics $[6,7]$.

Granite gneiss, a kind of metamorphic rock derived from igneous rocks, is commonly and widely distributed in engineering. Due to its low permeability and relatively high mechanical strength, granite gneiss is envisaged as one of the potential materials for underground oil storage, $\mathrm{CO}_{2}$ and shale gas storage, and radioactive waste disposal $[8,9]$.

As the relatively convenient and direct method, creep tests are usually used to characterize creep rate, identify different creep phases, and determine the long-term strength. Large numbers of investigations have been made through uniaxial and triaxial creep tests [10-14]. Martin and Chandler [15] argued that the long-term strength of rock corresponded to the stress at the onset of the microcrack-induced dilation. Chandler [16] further claimed that the long-term strength of rock was defined by the stress at volume strain reversal.
As Szczepanik et al. [17] pointed out, the sample would eventually fail under prolonged loading, which corresponded to the point at which strain reversal or sample dilation started, approximately $70 \%$ to $80 \%$ of the peak sample strength. Meanwhile, the time-dependent crack growth has been observed to estimate the long-term strength of rock [18-21]. However, the systematic studies on the long-term strength of rock are still lacking, especially in the quantitative way. Moreover, relatively little work has been done specially on the long-term strength of low-permeability rock as granite gneiss.

In this paper, we have performed the triaxial creep tests on granite gneiss under different pore pressures. Based on the test data, the long-term strength of the rock is investigated. Two new methods, tangent method and intersection method, of steady creep rate are put forward to confirm the long-term strength of rock in the quantitative way. The isochronous stress-strain curve method is also adopted to verify the results of the new methods. In the end, we discuss the effect of pore pressure on the long-term strength of rock in triaxial creep tests.

\section{Experimental Method and Materials}

A rock servo-controlled triaxial rheology test system is used to perform the triaxial compression tests and creep tests. 


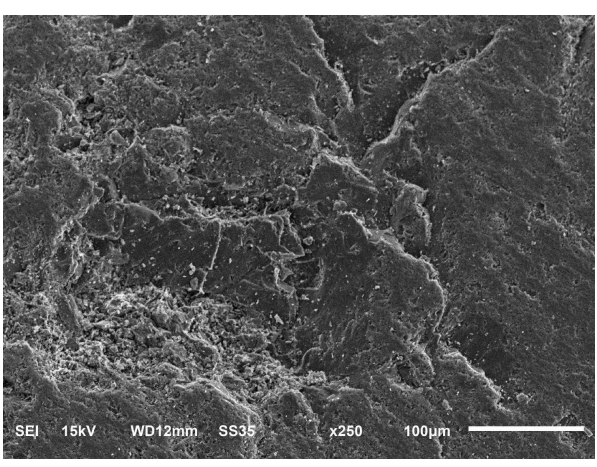

(a)

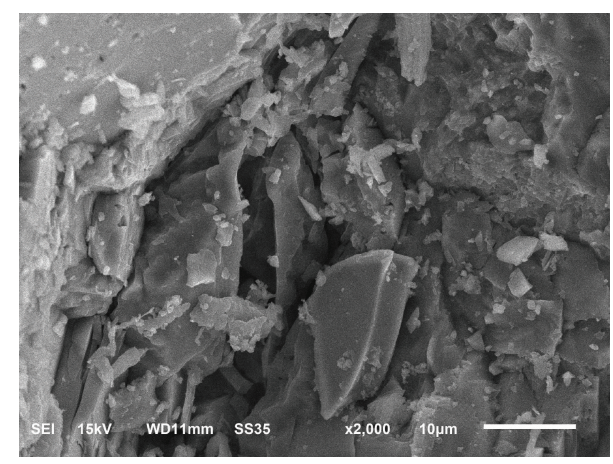

(b)

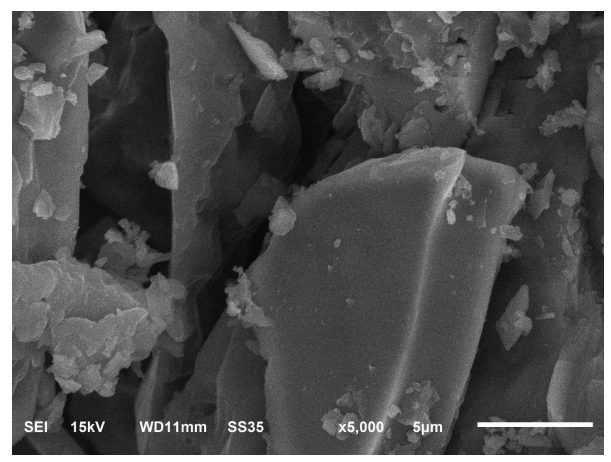

(c)

FIGURE 1: SEM photomicrographs of granite gneiss: (a) enlarged 250 times; (b) enlarged 2000 times; (c) enlarged 5000 times.

TABLE 1: Mean value of porosity and density.

\begin{tabular}{lcc}
\hline Specimen & Porosity $(\%)$ & Density $\left(\mathrm{g} \mathrm{cm}^{-3}\right)$ \\
\hline Granite gneiss & 1.79 & 2.61 \\
\hline
\end{tabular}

It can apply the confining pressure up to $60 \mathrm{MPa}$ and the maximum axial deviatoric stress of $500 \mathrm{MPa}$. The hydraulic pressures at the inlet and outlet can be automatically adjusted between 0 and $50 \mathrm{MPa}$ with an accuracy of $0.1 \mathrm{MPa}$. The test data of stress, strain, and permeability changes are automatically and accurately recorded at $5 \mathrm{~s}$ intervals and then transferred to a computer for further analysis.

The rock cores are granite gneiss, originally drilled from the early Cretaceous stratum of underground oil storage at a depth of $120 \mathrm{~m}$. The mineral components of the rock specimens are 33\% plagioclase, 32\% K-feldspar, 30\% quartz, and $5 \%$ biotite. The microstructure surface morphologies of the samples were obtained as shown in Figure 1 by scanning electron microscopy (SEM) technique. Most of the specimens are gray and there are no obvious fractures in the surface. Based on the basic parameter tests, the mean porosity and density of the six rock specimens are shown in Table 1. As a kind of low-permeability rock, the strength of rock is high and its structure is compact.

The tested specimens were prepared as cylindrical samples with a diameter of $50 \mathrm{~mm}$ and a length of $100 \mathrm{~mm}$ in accordance with the ISRM standard [22], as shown in Figure 2. Based on the field monitoring results, three groups
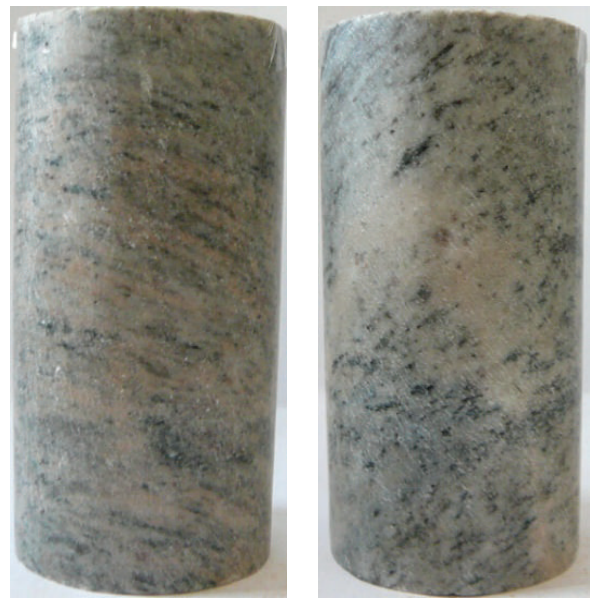

FIGURE 2: Typical rock specimens of granite gneiss.

of triaxial creep tests were carried out in drained condition with two identical specimens in each group. All the confining pressures $\left(\sigma_{3}\right)$ were $4.0 \mathrm{MPa}$ and the initial pore pressure differences $(\mathrm{Pi})$ were, respectively, 1.0, 2.0, and $3.0 \mathrm{MPa}$. Firstly, the confining pressure of $4.0 \mathrm{MPa}$ was applied to the specimen at a rate of $0.75 \mathrm{MPa} / \mathrm{min}$. And then the difference of pore pressure on the lower and upper sides of the specimen was applied by an injection pump at the same rate. The axial stress $\left(\sigma_{1}\right)$ was applied after $24 \mathrm{~h}$ in order to assure the tested specimens fully saturated. The axial deviatoric stress 
TABLE 2: Triaxial creep test conditions and preconfirmed deviatoric stress levels of the specimens.

\begin{tabular}{|c|c|c|c|c|c|}
\hline Specimens number & $\begin{array}{c}\text { Confining pressure } \\
(\mathrm{MPa})\end{array}$ & $\begin{array}{l}\text { Pore pressure } \\
\quad(\mathrm{MPa})\end{array}$ & Stress level & $\begin{array}{c}\text { Deviatoric stress } \\
(\mathrm{MPa})\end{array}$ & $\begin{array}{c}\text { Creep duration } \\
\text { (h) }\end{array}$ \\
\hline \multirow{5}{*}{$\mathrm{A} 1$} & \multirow{5}{*}{4} & \multirow{5}{*}{1} & 1 & 130 & 72 \\
\hline & & & 2 & 140 & 72 \\
\hline & & & 3 & 150 & 72 \\
\hline & & & 4 & 160 & 72 \\
\hline & & & 5 & 170 & 52 \\
\hline \multirow{5}{*}{$\mathrm{A} 2$} & \multirow{5}{*}{4} & \multirow{5}{*}{2} & 1 & 125 & 72 \\
\hline & & & 2 & 135 & 72 \\
\hline & & & 3 & 145 & 72 \\
\hline & & & 4 & 155 & 72 \\
\hline & & & 5 & 165 & 54 \\
\hline \multirow{5}{*}{ A3 } & \multirow{5}{*}{4} & \multirow{5}{*}{3} & 1 & 120 & 72 \\
\hline & & & 2 & 130 & 72 \\
\hline & & & 3 & 140 & 72 \\
\hline & & & 4 & 150 & 72 \\
\hline & & & 5 & 160 & 58 \\
\hline
\end{tabular}

$\left(\sigma_{1}-\sigma_{3}\right)$ was stepwise increased at a rate of $0.75 \mathrm{MPa} / \mathrm{min}$ until specimen failure. The first deviatoric stress level was set as $55 \% \sim 60 \%$ of the corresponding short-term peak strength. Based on the study of Cristescu [23] and Tsai et al. [24], the creep duration is determined by the concept of the stabilization boundary, defined by data points at the end of the primary creep. As for the granite gneiss in this study, the specimens were allowed to creep for a time interval of $72 \mathrm{~h}$ in each stress level. The deviatoric stress increments were designed for $10 \mathrm{MPa}$. The confining pressure and pore pressure were kept constant. All the specimens were quite homogeneous from the same rock block to minimize the scattering of test results attributable to variations of other factors. All tests were conducted in a thermally insulated room at constant temperature of $(20 \pm 0.3)^{\circ} \mathrm{C}$.

\section{Analysis of Long-Term Strength}

3.1. Creep Test Results. Taking into account the long-term strength of rock, it is necessary and significant to identify the time-dependent mechanical behavior of rock. Therefore, the triaxial creep tests were carried out for saturated granite gneiss under different pore pressures. Table 2 lists the creep test conditions and preconfirmed deviatoric stress levels of the specimens. The results of triaxial creep tests are illustrated in Figure 3. In the curves, the strain components $\varepsilon_{1}, \varepsilon_{3}$, and $\varepsilon_{v}$ denote the axial, lateral, and volumetric strains, respectively.

As can be seen from Figure 3, granite gneiss reflects the good creep mechanical behavior which is significantly affected by the loading condition. Under lower values of the deviatoric stress, the creep behavior can be divided into two stages, a primary creep stage with decreasing creep rate and a steady-state creep stage at constant creep rate. In the final stress level, all the specimens exhibited creep failure with a tertiary creep stage. During the creep process, the rock mechanical behavior in the steady-state creep stage has great significance, which decides whether the creep failure occurs eventually.

Based on the creep curves, the axial modulus and the ratio of lateral to axial strain in the complete creep test are obtained. The axial modulus is calculated by the ratio of the total axial deviatoric stress to the total axial strain. In the three groups of specimens numbered A1, A2, and A3 as shown in Table 2, the axial modulus is $30.02 \mathrm{GPa}, 29.06 \mathrm{GPa}$, and $26.74 \mathrm{GPa}$ while the ratio of lateral to axial strain is 0.95 , 0.97 , and 0.98 , respectively. As for the three groups of triaxial compression tests in accordance with the confining pressures and pore pressures of specimens A1, A2, and A3 [25], Young's modulus is $44.91 \mathrm{GPa}, 39.79 \mathrm{GPa}$, and $39.24 \mathrm{GPa}$, respectively. Moreover, Poisson's ratio is $0.36,0.37$, and 0.38 . Through comparison, the deformation parameters of the specimens are significantly affected by the long-term loading. The creep mechanical behavior of granite gneiss is obviously present.

3.2. Isochronous Stress-Strain Curve Method. The isochronous stress-strain curve method is an approach that has been used extensively for the creep evaluation of materials [26, 27]. As the most widely used and traditional method to confirm the long-term strength of rock, isochronous stress-strain curve method has been introduced into the test specification $[28,29]$. Isochronous stress-strain curves are the relationship curves of creep deformation and stress at the same time among a cluster of creep curves on different stress levels [30]. An isochronous stress-strain curve is firstly drawn by the stress-strain value of each intersection which is obtained by drawing a straight line that parallels the longitudinal axis on triaxial creep curves and making it intersect with the creep curves on different stress levels. The long-term strength of rock corresponds to the stress at the inflection point of the isochronous curves.

In this study, the specimens were allowed to creep for a time interval of $72 \mathrm{~h}$ in each stress level. As a result, $10 \mathrm{~h}$, 


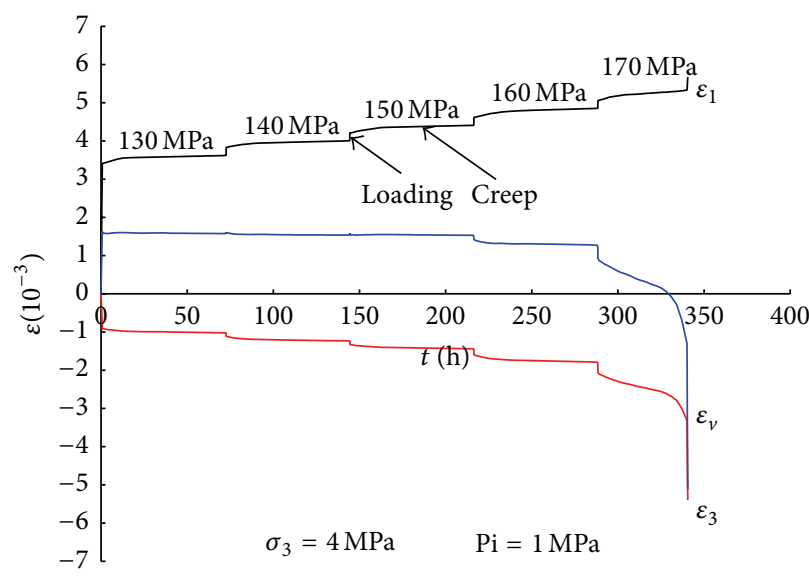

(a)

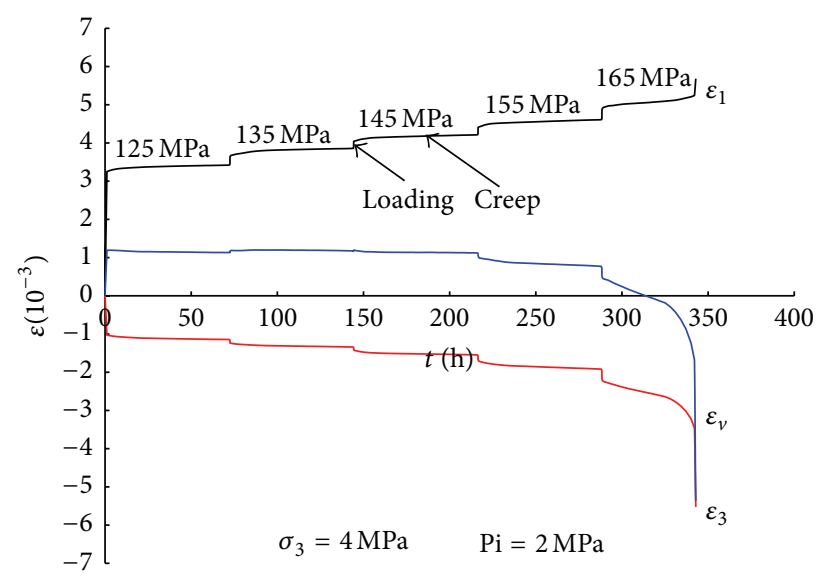

(b)

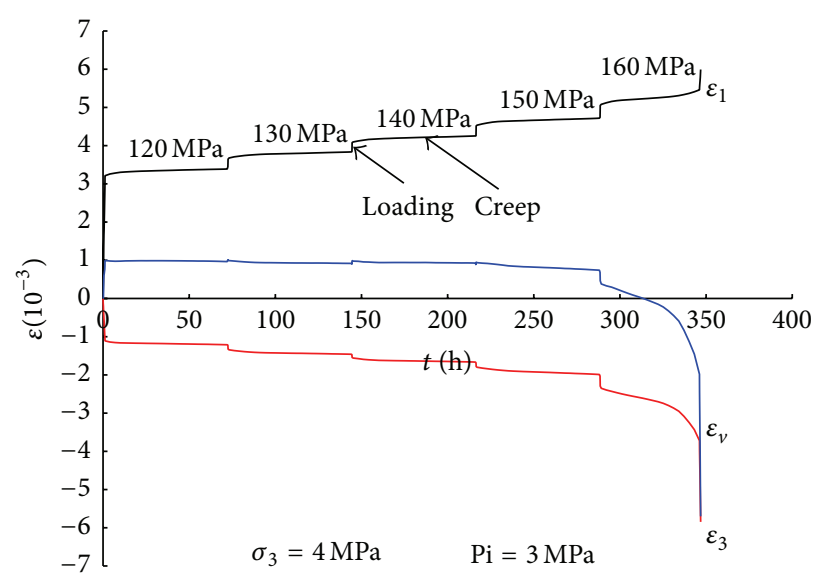

(c)

FIgURE 3: Triaxial creep test curves of granite gneiss: (a) $\sigma_{3}=4 \mathrm{MPa}, \mathrm{Pi}=1 \mathrm{MPa}$; (b) $\sigma_{3}=4 \mathrm{MPa}, \mathrm{Pi}=2 \mathrm{MPa}$; (c) $\sigma_{3}=4 \mathrm{MPa}, \mathrm{Pi}=3 \mathrm{MPa}$.

$20 \mathrm{~h}, 30 \mathrm{~h}, 40 \mathrm{~h}$, and $50 \mathrm{~h}$ in each stress level are determined as the time parameter in the isochronous stress-strain curves. Compared with the isochronous stress-axial strain and stressvolumetric strain curves, it is more obvious and convenient to find the inflection point in the isochronous stress-lateral strain curves (Figure 4).

With time, the isochronous curves show obvious nonlinear characteristics and then the inflection point occurs. When the deviatoric stress exceeds the stress value of the inflection point, the strain difference between the two immediate isochronous curves increases largely under high deviatoric stress.

3.3. Tangent Method of Steady Creep Rate. As mentioned before, the steady creep rate plays an important role in the confirmation of the long-term strength. In the steady creep rate curves, the long-term strength corresponds to the stress of the inflection point. However, in practice, it is difficult to quantify the long-term strength just relying on the visual observation and furthermore sometimes the inflection point of the curves is vague. In order to solve the problem, we introduce the tangent of the steady creep rate curves. The acute angles $(\alpha)$ between the tangents and the $x$-axis (deviatoric stress axis) are set as the key parameter in this method.
The long-term strength of rock is quantitatively confirmed based on the intersection point between the tangents of proper angles and the $x$-axis.

The lateral steady creep rate is also chosen as the research subject. All the specimens experience five stress levels before the failure. The steady creep rate curves are obtained through the fitting of exponential function on the five points. In the curves (shown in Figure 5), $\dot{\varepsilon}_{3}$ is the lateral steady creep rate.

In Figure 5(a), a series of tangents of different angles are drawn on the curves. The angles are in the range of $0^{\circ}$ and $90^{\circ}$ by $10^{\circ}$. Among them, the tangent of $\alpha=0^{\circ}$ is parallel to the $x$-axis and the tangent of $\alpha=90^{\circ}$ is parallel to the $y$ axis. There is no need to take the two tangents into account in the study of the long-term strength. The angles $\alpha$ of the following eight tangents are listed as $10^{\circ}, 20^{\circ}, 30^{\circ}, 40^{\circ}, 50^{\circ}, 60^{\circ}$, $70^{\circ}$, and $80^{\circ}$. The intersections of the tangents and the $x$-axis are sequentially named $A, B, C, D, E, F, G$, and $H$. Eight lines of $X=A, B, C, D, E, F, G, H$ are drawn and all intersect with the curves. Therefore, the steady creep rate curves contain $A B, B C, C D, D E, E F, F G$, and $G H$ interval. Then, we need to choose the proper interval. The basic principle is that the inflection point of the curves must be in the interval. Through comparison and analyses, the smallest interval of EF just 


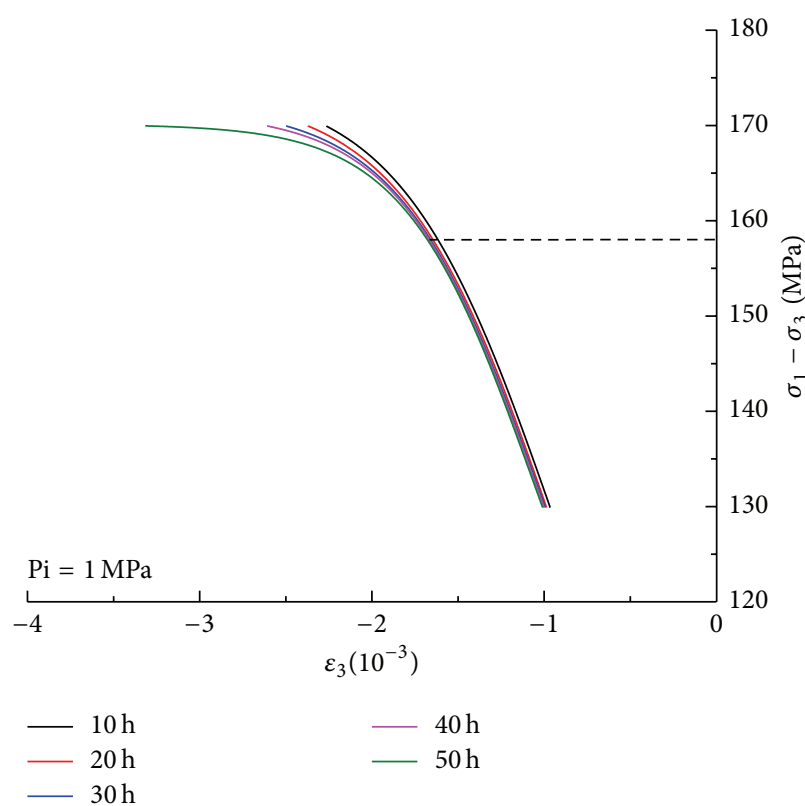

(a)

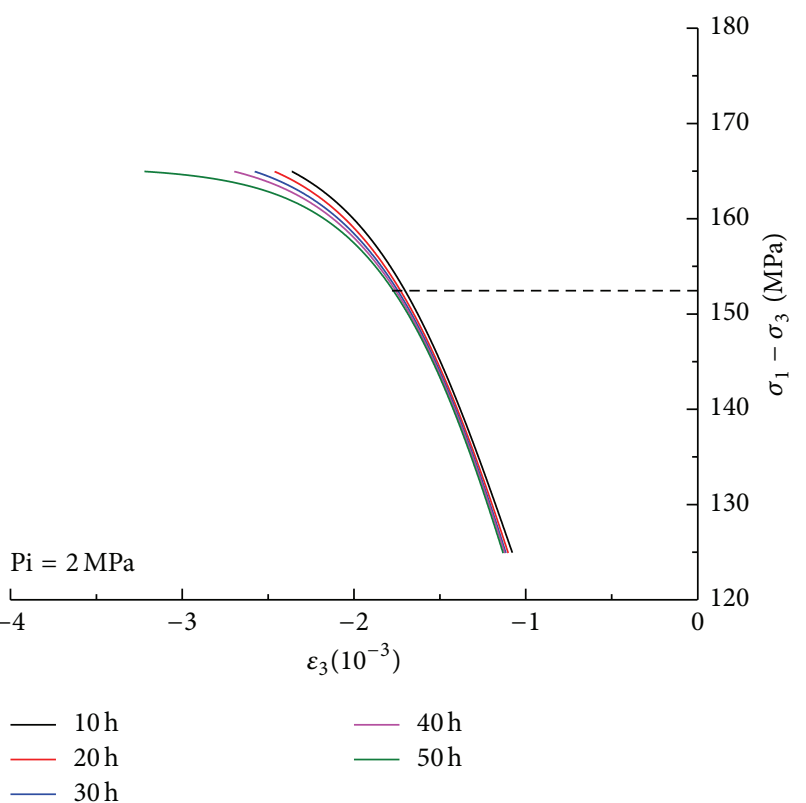

(b)

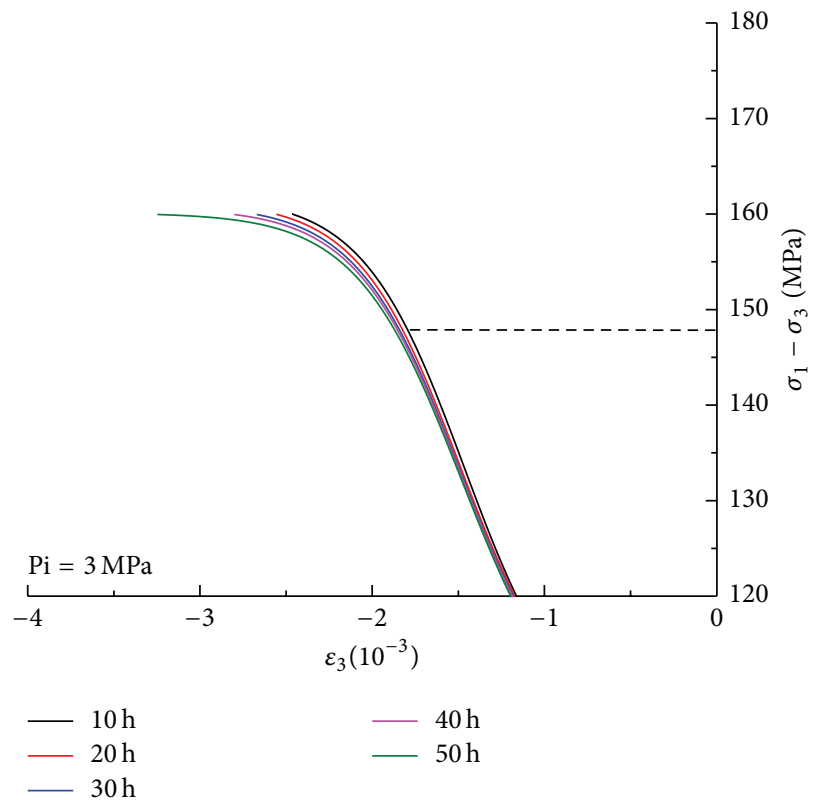

(c)

FIGURE 4: Isochronous stress-lateral strain curves of granite gneiss: (a) $\sigma_{3}=4 \mathrm{MPa}, \mathrm{Pi}=1 \mathrm{MPa}$; (b) $\sigma_{3}=4 \mathrm{MPa}, \mathrm{Pi}=2 \mathrm{MPa}$; (c) $\sigma_{3}=4 \mathrm{MPa}$, $\mathrm{Pi}=3 \mathrm{MPa}$.

contains the inflection point of the curves. The corresponding angles $\alpha$ are between $50^{\circ}$ and $60^{\circ}$. The deviatoric stress values in $E F$ interval are the long-term strength range of the specimens.

For the rock specimens under other pore pressures, the angles between $50^{\circ}$ and $60^{\circ}$ are also suitable for the confirmation of the long-term strength. This is shown in Figures 5(b) and 5(c). Through the tangent method, the long-term strength range can be quantitatively and accurately confirmed based on the angles $\alpha$.
3.4. Intersection Method of Steady Creep Rate. In the process of triaxial creep test, granite gneiss experiences not only the volumetric compression, but also the volumetric dilatancy. At low level of stress, the rock deformation is in compression while the axial steady creep rate is greater than the volumetric steady creep rate. Under high stress, the volumetric steady creep rate increases sharply and becomes greater than the axial steady creep rate. The rock samples experience significant volumetric dilatancy and exhibit creep failure quickly. Therefore, the axial and volumetric curves of steady creep 


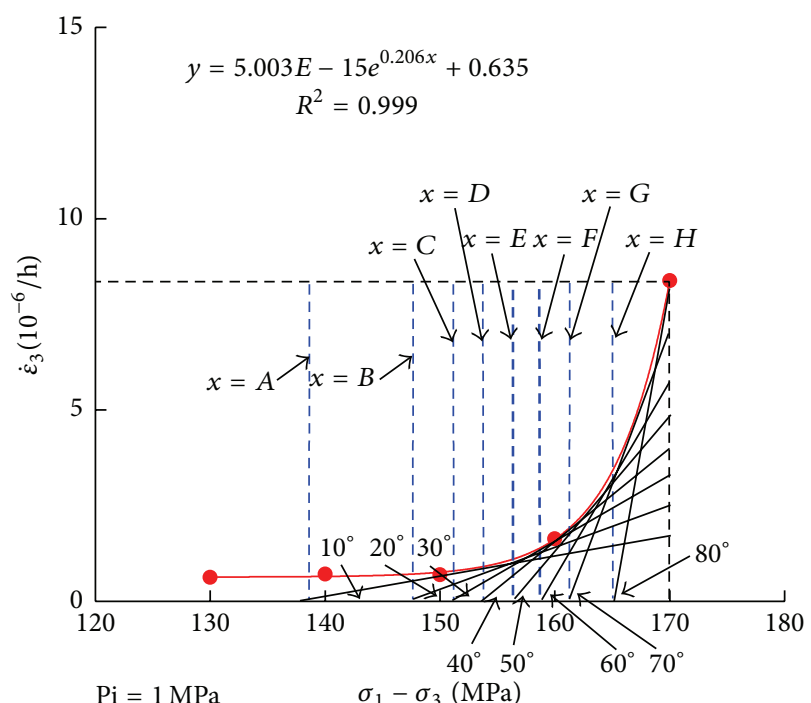

(a)

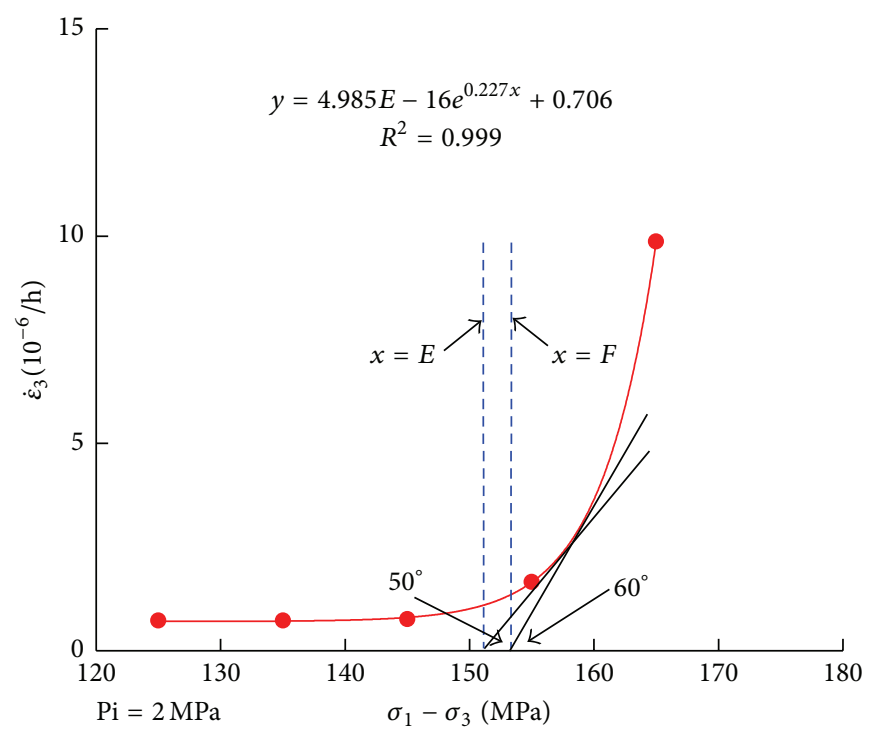

(b)

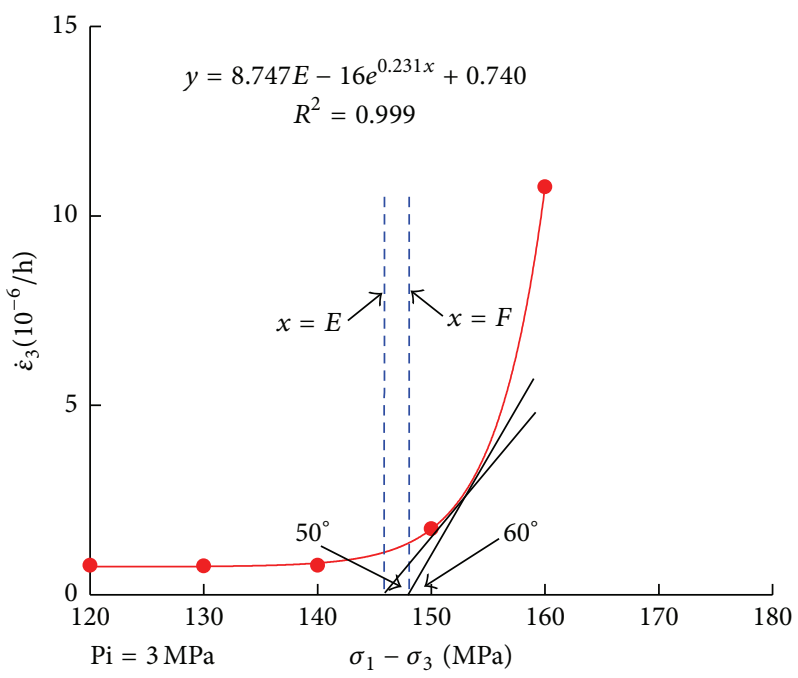

(c)

Figure 5: Curves of tangent method of steady creep rate: (a) $\sigma_{3}=4 \mathrm{MPa}, \mathrm{Pi}=1 \mathrm{MPa}$; (b) $\sigma_{3}=4 \mathrm{MPa}, \mathrm{Pi}=2 \mathrm{MPa} ;(\mathrm{c}) \sigma_{3}=4 \mathrm{MPa}, \mathrm{Pi}=3 \mathrm{MPa}$.

rate exhibit an intersection point. It is the critical point of rock compression and volumetric dilatancy. Based on the actual deformation characteristics of the samples, the longterm strength is defined by the stress at the intersection point.

The steady creep rate curves are obtained in the same manner with the tangent method. The exponential function is also used for the curves fitting. In the curves (Figure 6), $\dot{\varepsilon}_{1}$ and $\dot{\varepsilon}_{v}$ refer to the axial and volumetric steady creep rate. The stress value of the intersection point is the long-term strength in this method. The intersection method can quantitatively obtain the long-term strength of rock conveniently.

\section{Comparison and Discussion}

4.1. Comparison of the Three Methods to Confirm the LongTerm Strength. Based on the triaxial creep test data, isochronous stress-strain curve method, tangent method, and intersection method of steady creep rate are used to confirm the long-term strength of the rock specimens under different pore pressures. The results of isochronous stress-strain curve method are used as the reference, as the method is most commonly used. The two new proposed quantitative methods are compared on the basis of the reference. In Table $3, \sigma_{\infty}$ denotes the long-term strength of the rock specimens. $D$ is the percentage of the difference in the reference while the difference is between new method results and the reference.

According to Table 3 , the results ranges of the tangent method are precise. The results ranges basically contain the results of the other two methods. Compared with the results of the isochronous curve method, the results are in the fluctuation between $-0.8 \%$ and $0.7 \%$ of the reference. It is noticed that the results of the intersection method are very close to that of the isochronous curve method. The maximum difference of the two methods is $0.5 \%$ of the reference. 


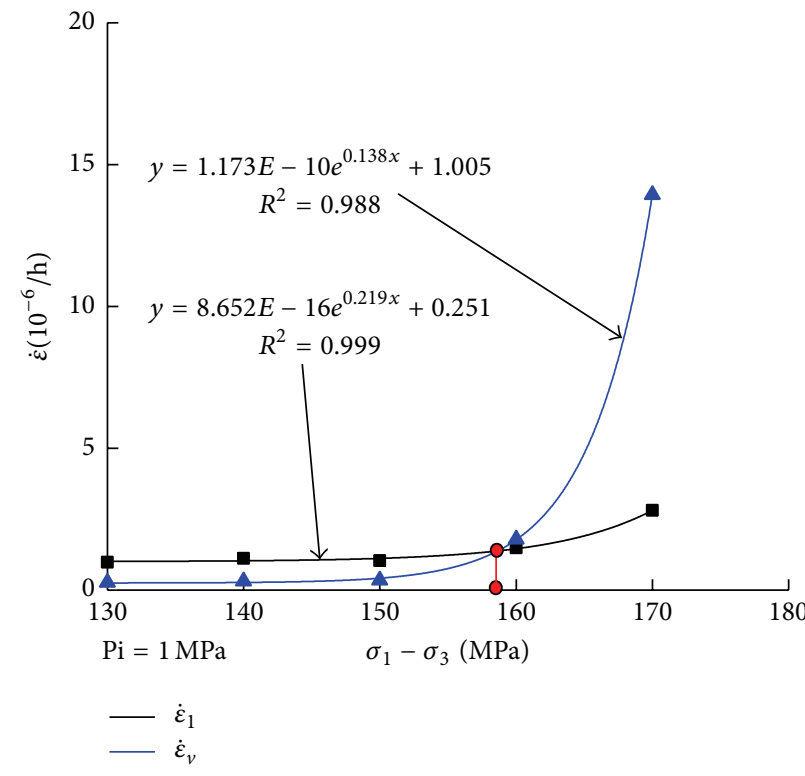

(a)

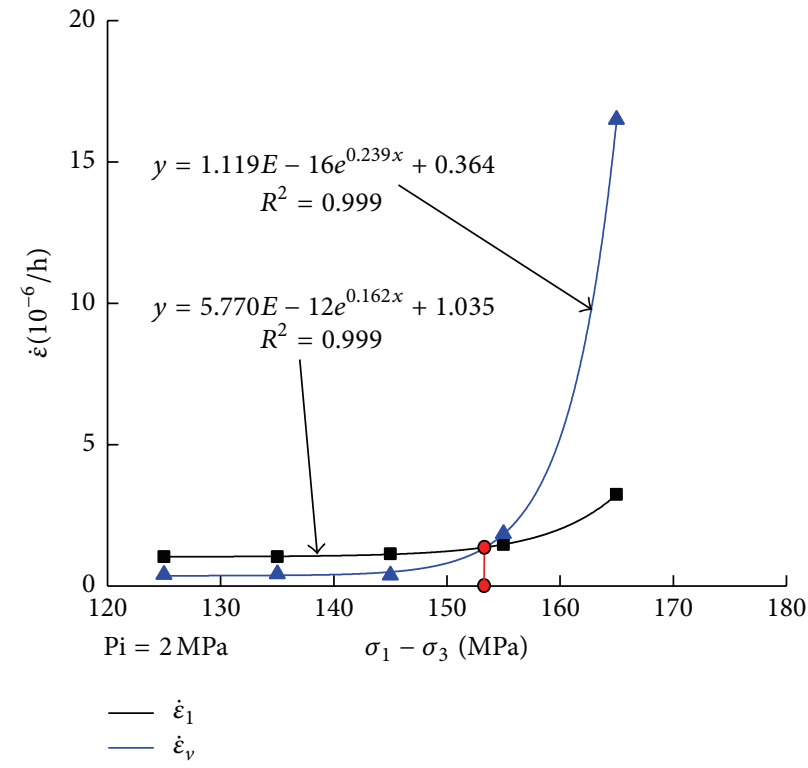

(b)

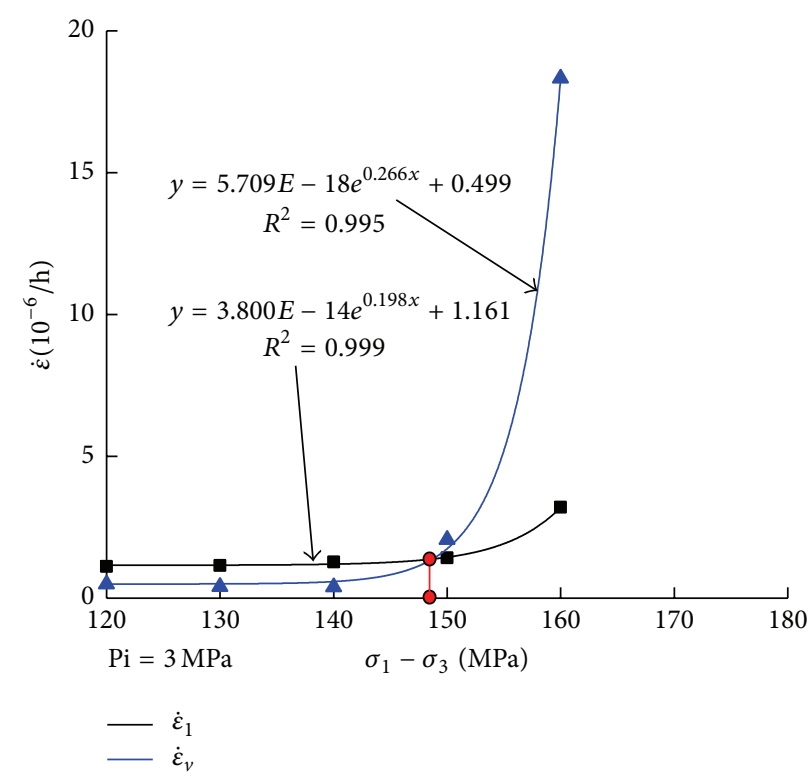

(c)

Figure 6: Curves of intersection method of steady creep rate: (a) $\sigma_{3}=4 \mathrm{MPa}, \mathrm{Pi}=1 \mathrm{MPa}$; (b) $\sigma_{3}=4 \mathrm{MPa}, \mathrm{Pi}=2 \mathrm{MPa}$; (c) $\sigma_{3}=4 \mathrm{MPa}, \mathrm{Pi}=$ $3 \mathrm{MPa}$.

TABLE 3: Results comparison of the three methods to confirm the long-term strength.

\begin{tabular}{|c|c|c|c|c|c|}
\hline \multirow{2}{*}{$\begin{array}{l}\text { Specimen } \\
\text { number }\end{array}$} & \multirow{2}{*}{$\begin{array}{l}\text { Isochronous stress-strain curve method } \\
\qquad \sigma_{\infty} / \mathrm{MPa}\end{array}$} & \multicolumn{2}{|c|}{ Tangent method of steady creep rate } & \multicolumn{2}{|c|}{ Intersection method of steady creep rate } \\
\hline & & $\sigma_{\infty} / \mathrm{MPa}$ & $D / \%$ & $\sigma_{\infty} / \mathrm{MPa}$ & $D / \%$ \\
\hline A1 & 157.8 & $156.8 \sim 158.6$ & $-0.6 \sim 0.5$ & 158.4 & 0.4 \\
\hline $\mathrm{A} 2$ & 152.4 & 151.6 153.4 & $-0.5 \sim 0.7$ & 153.2 & 0.5 \\
\hline A3 & 147.6 & $146.4 \sim 148.2$ & $-0.8 \sim 0.4$ & 148.4 & 0.5 \\
\hline
\end{tabular}


In conclusion, the tangent method and intersection method of steady creep rate are very precise and suitable for the confirmation of the long-term strength of granite gneiss, which may be applied in the long-term stability analysis of rock engineering.

4.2. Effect of Pore Pressure on the Long-Term Strength. It is also apparent from Table 3 that pore pressure has influence on the long-term strength of the rock specimens. Take the results of intersection method as an example. Under a confining pressure of $4 \mathrm{MPa}$, when the pore pressure increases from $1 \mathrm{MPa}$ to $3 \mathrm{MPa}$, the long-term strength decreases from $158.4 \mathrm{MPa}$ to $148.4 \mathrm{MPa}$. The higher the pore pressure, the lower the long-term strength of rock.

It can also be noticed from Figure 3 that the creep deformation is larger in higher pore pressure while the creep rate is greater. This phenomenon is more obvious at high level of stress. According to the effective stress concept, the pore pressure in the specimens causes a decrease in the confining pressure. To sum up, the long-term strength of rock is affected by the pore pressure.

\section{Conclusions}

Granite gneiss, taken from underground oil storage, was tested in a series of triaxial creep tests under different pore pressures. The long-term strength of rock is investigated and studied in this paper experimentally. Based on the results obtained, conclusions can be made as follows:

(1) The tangent method of steady creep rate is proposed to confirm the long-term strength of rock in the quantitative way. The acute angles $(\alpha)$ between the tangents and the $x$-axis (deviatoric stress axis) are introduced as the key parameter in this method. The smallest interval just contains the inflection point of the curves and is related to the long-term strength.

(2) Based on the deformation characteristics of the samples, the stress at the intersection point of the axial and volumetric steady creep rate curves is defined as the long-term strength of rock. This new method is more convenient to obtain the long-term strength of rock.

(3) The common isochronous stress-strain curve method is also adopted and used as the reference. Through the results comparison, the results ranges of the tangent method are precise with the fluctuation between $-0.8 \%$ and $0.7 \%$ of the reference values. Moreover, the results of the intersection method are very close to that of the isochronous curve method with the maximum difference of $0.5 \%$ of the reference values.

(4) The two new proposed methods, tangent method and intersection method, are very precise and suitable for the determination of long-term strength of rock in the quantitative way. It is also apparent that pore pressure has influence on the long-term strength of the rock specimens.

Nevertheless, the two methods are proposed and implemented based on the rock specimens of granite gneiss. In the future, the two new methods are to be validated by more test data with various rocks and loading conditions to show the generalization ability in the study of the long-term strength of rock.

\section{Conflict of Interests}

The authors declare that there is no conflict of interests regarding the publication of this paper.

\section{Acknowledgment}

The work was supported by the National Natural Science Foundation of China (nos. 11172090, 51209075, 11272113, and 51479049).

\section{References}

[1] S.-Q. Yang, H.-W. Jing, and L. Cheng, "Influences of pore pressure on short-term and creep mechanical behavior of red sandstone," Engineering Geology, vol. 179, no. 4, pp. 10-23, 2014.

[2] P. Le Comte, "Creep in rock salt," The Journal of Geology, vol. 73, no. 3, pp. 469-484, 1965.

[3] D. Lockner and J. Byerlee, "Acoustic emission and creep in rock at high confining pressure and differential stress," Bulletin of the Seismological Society of America, vol. 67, no. 2, pp. 247-258, 1977.

[4] E. Boidy, A. Bouvard, and F. Pellet, "Back analysis of timedependent behaviour of a test gallery in claystone," Tunnelling and Underground Space Technology, vol. 17, no. 4, pp. 415-424, 2002.

[5] B. Mishra and P. Verma, "Uniaxial and triaxial single and multistage creep tests on coal-measure shale rocks," International Journal of Coal Geology, vol. 137, pp. 55-65, 2015.

[6] S. Nadimi and K. Shahriar, "Experimental creep tests and prediction of long-term creep behavior of grouting material," Arabian Journal of Geosciences, vol. 7, no. 8, pp. 3251-3257, 2014.

[7] M. Aubertin, L. Li, and R. Simon, "A multiaxial stress criterion for short-and long-term strength of isotropic rock media," International Journal of Rock Mechanics and Mining Sciences, vol. 37, no. 8, pp. 1169-1193, 2000.

[8] C.-F. Tsang, F. Bernier, and C. Davies, "Geohydromechanical processes in the Excavation Damaged Zone in crystalline rock, rock salt, and indurated and plastic clays-in the context of radioactive waste disposal," International Journal of Rock Mechanics and Mining Sciences, vol. 42, no. 1, pp. 109-125, 2005.

[9] H.-L. Wang, W.-Y. Xu, J.-F. Shao, and F. Skoczylas, "The gas permeability properties of low-permeability rock in the process of triaxial compression test," Materials Letters, vol. 116, pp. 386388, 2014.

[10] Z.-L. Zhang, W.-Y. Xu, W. Wang, and R.-B. Wang, “Triaxial creep tests of rock from the compressive zone of dam foundation in Xiangjiaba Hydropower Station," International Journal of Rock Mechanics and Mining Sciences, vol. 50, pp. 133-139, 2012.

[11] M. J. Heap, P. Baud, P. G. Meredith, A. F. Bell, and I. G. Main, "Time-dependent brittle creep in Darley Dale sandstone," Journal of Geophysical Research: Solid Earth, vol. 114, no. 7, Article ID B07203, pp. 1-22, 2009.

[12] P. Baud and P. G. Meredith, "Damage accumulation during triaxial creep of Darley Dale sandstone from pore volumometry and acoustic emission," International Journal of Rock Mechanics and Mining Sciences, vol. 34, no. 3-4, pp. 24.el-24.e10, 1997. 
[13] S.-Q. Yang and Y.-Z. Jiang, "Triaxial mechanical creep behavior of sandstone," Mining Science and Technology, vol. 20, no. 3, pp. 339-349, 2010.

[14] N. L. Carter, S. T. Horseman, J. E. Russell, and J. Handin, "Rheology of rocksalt," Journal of Structural Geology, vol. 15, no. 9-10, pp. 1257-1271, 1993.

[15] C. D. Martin and N. A. Chandler, "The progressive fracture of Lac du Bonnet granite," International Journal of Rock Mechanics and Mining Sciences and, vol. 31, no. 6, pp. 643-659, 1994.

[16] N. A. Chandler, "Quantifying long-term strength and rock damage properties from plots of shear strain versus volume strain," International Journal of Rock Mechanics and Mining Sciences, vol. 59, pp. 105-110, 2013.

[17] Z. Szczepanik, D. Milne, K. Kostakis, and E. Eberhardt, "Long term laboratory strength tests in hard rock," in Proceedings of the 10th ISRM Congress, pp. 1179-1184, International Society for Rock Mechanics, Sandton, South Africa, September 2003.

[18] B. J. S. Wilkins, "Slow crack growth and delayed failure of granite," International Journal of Rock Mechanics and Mining Sciences \& Geomechanics Abstracts, vol. 17, no. 6, pp. 365-369, 1980.

[19] K. Miura, Y. Okui, and H. Horii, "Micromechanics-based prediction of creep failure of hard rock for long-term safety of highlevel radioactive waste disposal system," Mechanics of Materials, vol. 35, no. 3-6, pp. 587-601, 2003.

[20] A. Lavrov, "The Kaiser effect in rocks: principles and stress estimation techniques," International Journal of Rock Mechanics and Mining Sciences, vol. 40, no. 2, pp. 151-171, 2003.

[21] Y. Nara, M. Takada, D. Mori, H. Owada, T. Yoneda, and K. Kaneko, "Subcritical crack growth and long-term strength in rock and cementitious material," International Journal of Fracture, vol. 164, no. 1, pp. 57-71, 2010.

[22] C. E. Fairhurst and J. A. Hudson, "Draft ISRM suggested method for the complete stress-strain curve for intact rock in uniaxial compression," International Journal of Rock Mechanics and Mining Sciences, vol. 36, no. 3, pp. 279-289, 1999.

[23] N. D. Cristescu, "Viscoplasticity of geomaterials", in ViscoPlastic Behaviour of Geomaterials, pp. 103-207, Springer Vienna, 1994.

[24] L. S. Tsai, Y. M. Hsieh, M. C. Weng, T. H. Huang, and F. S. Jeng, "Time-dependent deformation behaviors of weak sandstones," International Journal of Rock Mechanics and Mining Sciences, vol. 45, no. 2, pp. 144-154, 2008.

[25] L. Liu, W.-Y. Xu, H.-L. Wang, R.-B. Wang, and W. Wang, "Experimental studies on hydro-mechanical properties of metamorphic rock under hydraulic pressures," European Journal of Environmental and Civil Engineering, 2015.

[26] W. Koves and M. Zhao, "Comparison of the Isochronous method and a time-explicit model for creep analysis," in Proceedings of the Pressure Vessels and Piping Conference (PVP '08), pp. 751-759, American Society of Mechanical Engineer, Chicago, Ill, USA, July 2008.

[27] M. Zhao and W. Koves, "Isochronous stress-strain method with general state of stress and variable loading conditions for creep evaluation," Journal of Pressure Vessel Technology, vol. 134, no. 5, Article ID 51205, pp. 1-6, 2012.

[28] L.-Q. Li, W.-Y. Xu, W. Wang, Y.-Q. Guo, and H.-B. Zhao, "Estimation of long-term strength for Xiangjiaba sandstone based on creep tests," Engineering Mechanics, vol. 27, no. 11, pp. 127136, 2010.
[29] The Professional Standards Compilation Group of People's Republic of China, SL264-2001 Specification for Rock Tests in Water Conservancy and Hydroelectric Engineering, Water Power Press, Beijing, China, 2001, (Chinese).

[30] Y.-J. Xie, Q. Fu, G.-C. Long, K.-R. Zheng, and H. Song, "Creep properties of cement and asphalt mortar," Construction and Building Materials, vol. 70, pp. 9-16, 2014. 

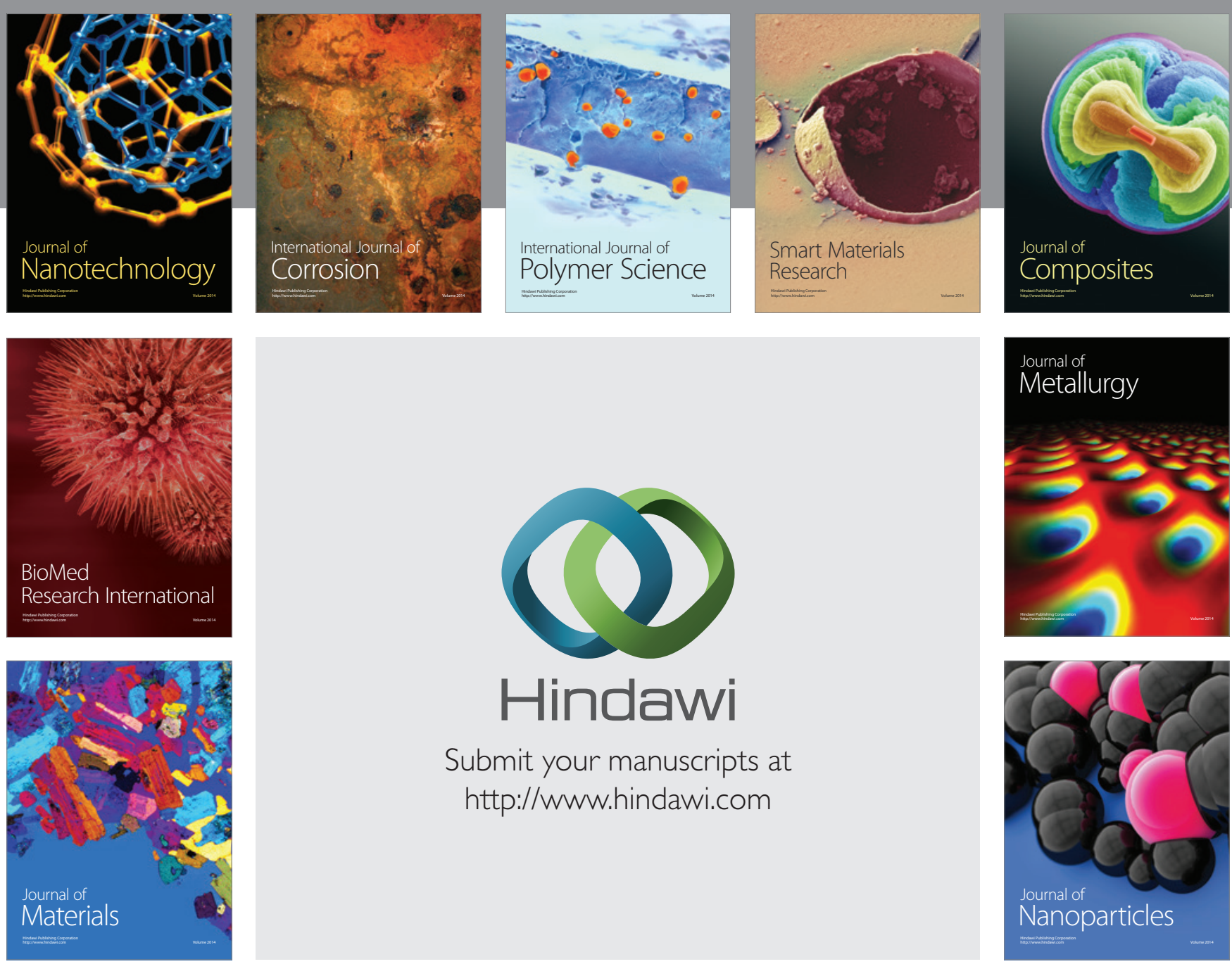

Submit your manuscripts at http://www.hindawi.com
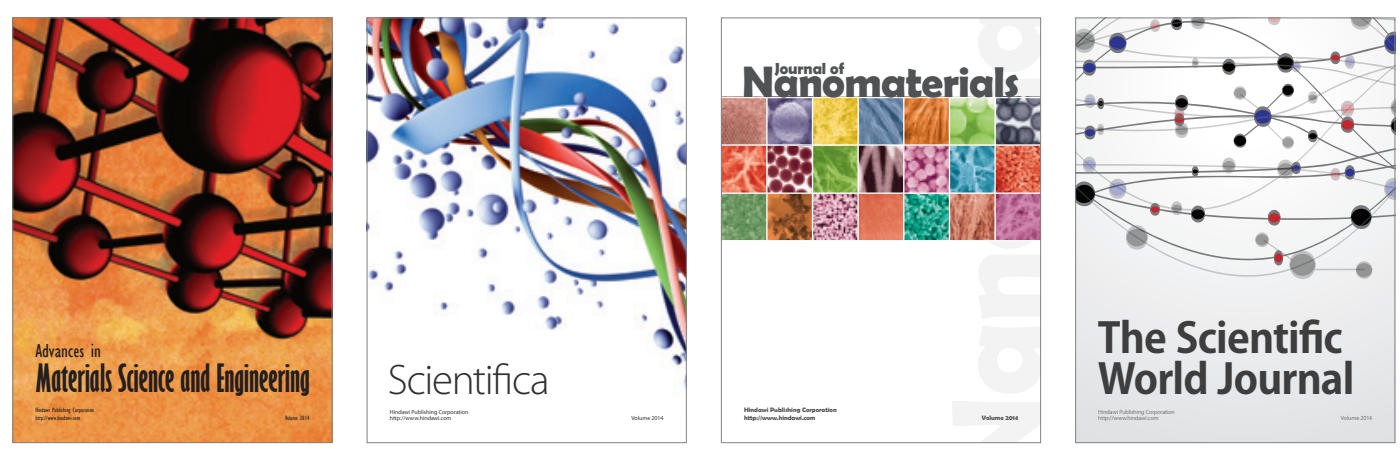

\section{The Scientific World Journal}
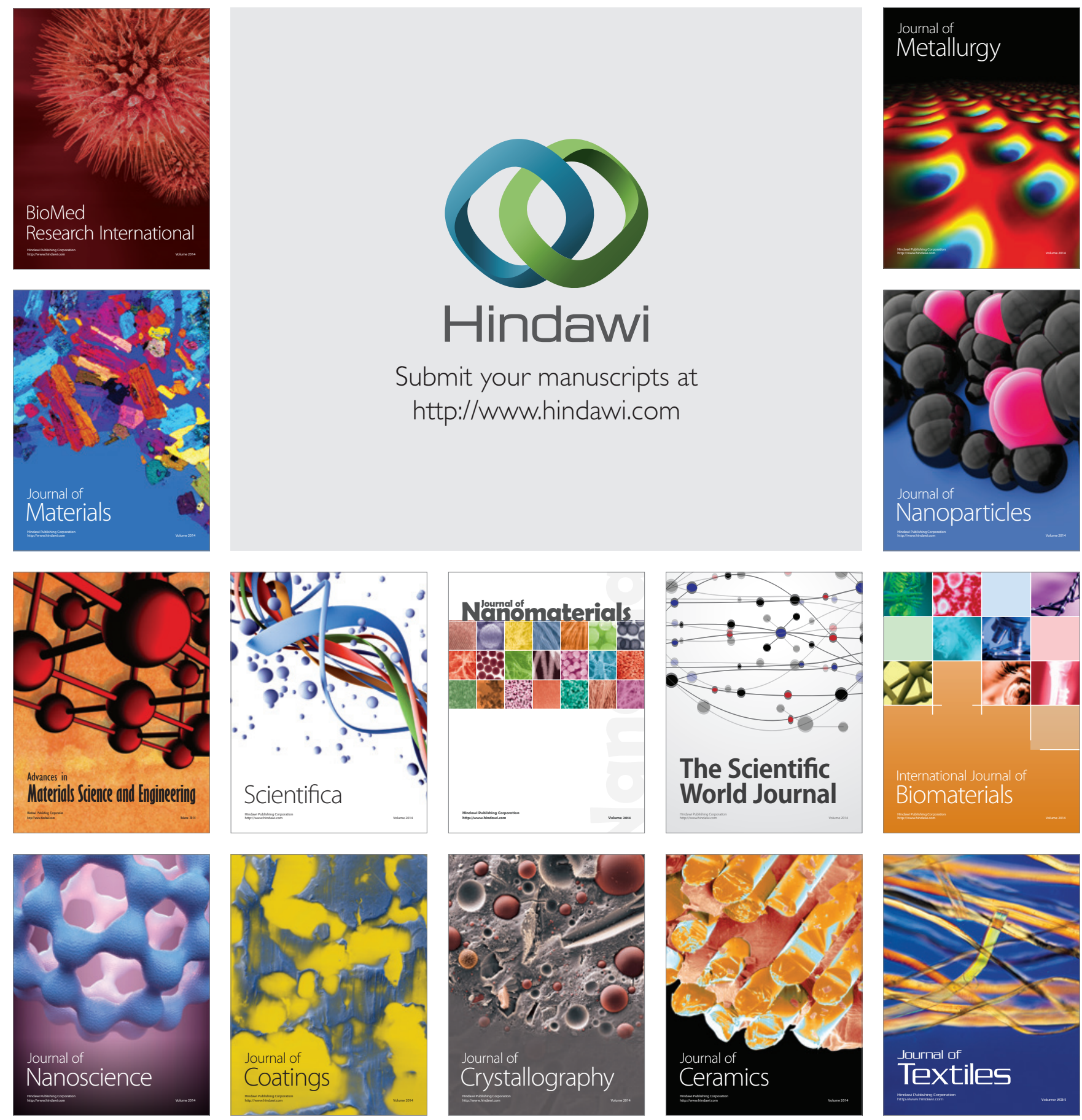